\title{
Pascal Spreading of Short-Term Interest Rate Contracts
}

\author{
John J. Merrick, Jr.*
}

June 2000

*Visiting Professor of Finance, Stern School of Business, New York University, 44 West Fourth Street, New York, NY 10012. The author thanks Colin Negrych and Ken Garbade for comments at an earlier stage. Each are absolved from any remaining errors. 


\begin{abstract}
This paper examines the spreading and pricing of short-term interest rate futures contracts and shows how traditional types of calendar spread positions can emerge as explicit arbitrage solutions. A specific set of intuitive spreading structures - "Pascal's Spreading Triangle" - arises when the underlying daily risk factors are identified as the stochastic coefficients of a high-ordered polynomial approximation to the yield curve. No empirically estimated hedge ratios are required for these arbitrage strategies. Application of this Pascal Spreads framework to pricing and trading the LIFFE's Short Sterling deposit futures market over the 1989 to 1998 sample period reveals that the LIFFE's Short Sterling arbitrage sector's efficiency has improved markedly over time. The improvement over the decade coincides with the dramatic declines in futures trading transactions costs. As a byproduct, the framework extracts and measures the quantitative impact of the $\mathrm{Y} 2 \mathrm{~K}$ millennium-turn pricing distortion on the December 1999 Short Sterling futures contract.
\end{abstract}




\section{Introduction}

The trading volume and open interest of short-term deposit rate futures contracts dwarf those of other fixed income and equity-based contracts. Since current and expected future levels of short-term interest rates affect almost every economic and financial decision, the scale of this activity should be no surprise. Much of this deposit rate futures trading interest stems from two important forms of activity: contract calendar spreads and contract strips. The quoted prices of deposit futures contracts form a discrete term structure of interest rates for successive three-month forward intervals. Speculators express views on relative levels of interest rates at two or more points along this forward rate term structure through calendar spread trading. Hedgers can lock-in the current term structure of rates over a string of future periods through deposit futures contract strips. But regardless of their own hedging or speculative motives for trading, all end users of deposit futures contracts rely on an arbitrage sector to enforce fair relative pricing relationships. ${ }^{1}$

For deposit contracts, arbitrage versus the interbank deposit market places some restrictions on individual deposit futures contract prices. ${ }^{2}$ However, relationships between adjacent futures contracts seem to be priced much tighter than can be motivated by interbank cash deposit market/deposit futures market arbitrage alone given the interbank market's transaction bid-ask spread. Low-cost deposit futures calendar spread trading alone appears to enforce the orderliness of deposit futures pricing in the major deposit futures markets. Since hedgers and speculators alike benefit from the pricing results of such arbitrage trading, insight 
into the underpinnings of deposit calendar spread pricing and trading is of general market interest.

This paper develops an understanding of deposit futures contract calendar spread arbitrage within a particular representation of the futures yield curve. The specific context is a well-known mathematical formulation: a high-order polynomial approximation representation of the term structure. But the paper's focus on a deposit rate futures contract spreader's risk perspective is a departure from the usual "curve-fitting" application of such a model. Here, thinking first about multidimensional trading risks, and only later about curve-fitting precision, follows the general emphasis of factor models in understanding multiple risk dimensions.

The analysis here produces some new insights into the natures of calendar spread trading design, arbitrage activity and risk structure along the yield curve. First, risk-controlled spread positions producing stationary value series relevant for spread trading do exist. Second, the precise form of trading conforms to an analytical solution termed here as "Pascal's Spreading Triangle." The solution collapses neatly to a series of sequential spreads in adjacent contracts: spreads; spreads of spreads; spreads of spreads of spreads; and so on. Importantly, no empirically estimated hedge ratios are required to implement this spread trading paradigm. Thus, not only can the high-order polynomial approach "fit" a deposit contract strip arbitrarily well, but the approach delivers intuitive trading forms that can be applied by arbitrage traders to maintain pricing discipline.

The paper applies the framework to examine changes in the pricing efficiency of the London International Financial Futures Exchange's Short Sterling deposit futures contract 
market over the period between 1989 and 1998. For these ten years' worth of Short Sterling deposit rate futures price data, the Pascal spread structures produce sensible results and reveal how the arbitrage sector's efficiency has improved over time in this market.

\section{Hedging and Spreading}

Specific hedging and spreading solutions depend on specific analytical term structure frameworks. Two particular term structure representations examined here are (1) the factor model and (2) the high-order polynomial approximation. The factor model describes the term structure as being generated by equilibrium pricing of a parsimonious number of risk factors. The empirical content of the model relies on the estimation - from historical data - of the term structure's implicit factors via the statistical methods of factor analysis or principal components. Garbade (1996) and Litterman and Scheinkman (1991) apply the factor analytic framework to US Treasury yields. Campbell, Lo and MacKinlay (1997) review the extensive application of the factor approach in equity valuation.

Alternatively, from Weiestrass's Approximation Theorem, a suitably high-order polynomial function can approximate the term structure over a given interval with an arbitrary degree of precision. ${ }^{3}$ Chambers, Carleton and Waldman (1984) apply polynomial functions of degrees one through five to the spot yield curve implied from US Treasury notes and bonds. ${ }^{4}$

In contrast to their emphasis on using high-order polynomial functions for empirical curve-fitting ends, the strategy here focuses on this model's implications for risk management.

Consider a forward deposit rate contract strip consisting of $\mathrm{n}$ different maturities, where each successive strip maturity is equally spaced in time, one period unit apart. Let $\mathrm{N}_{(1 \times \mathrm{n})}$ be the 
potential ( $1 \times n$ ) vector of positions in the strip and let $R_{(n \times 1)}$ be a (n x 1) vector of forward interest rates for each strip component. Now, consider a general $k+1$ factor representation of this forward interest rate vector. In particular, let

$$
\mathrm{R}_{(\mathrm{n} \times 1)}=\mathrm{T}_{(\mathrm{n} \times \mathrm{k}+1)} * \mathrm{~B}_{(\mathrm{k}+1 \times 1)}
$$

where $T_{(n \times k+1)}$ is a set of factor loadings and $B_{(k+1 \times 1)}$ is a $k+1 \times 1$ vector of factors describing the current forward yield curve. For a predetermined factor loading matrix, the portfolio's value risk depends solely on changes in $\mathrm{B}_{(\mathrm{k}+1 \times 1)}$, the vector of yield curve factors. Thus, interest rate changes, $\mathrm{dR}_{(\mathrm{n} \times 1)}$, are expressed as a function of $\mathrm{dB}_{(\mathrm{k}+1 \times 1)}$, the vector of factor innovations:

$$
\mathrm{dR}_{(\mathrm{n} \times 1)}=\mathrm{T}_{(\mathrm{n} \times \mathrm{k}+1)} * \mathrm{~dB}_{(\mathrm{k}+1 \times 1)}
$$

Consider $\mathrm{dV}$, the dollar payoff to a portfolio consisting of the (arbitrary) position vector $\mathrm{N}_{(\mathrm{n} \times 1)}$, where $\mathrm{q}$ is a scalar denoting the dollar value of a forward rate move:

$$
\begin{aligned}
\mathrm{dV} & =\mathrm{q} * \mathrm{~N}_{(1 \times \mathrm{n})} * \mathrm{dR}_{(\mathrm{n} \times 1)} \\
& =\mathrm{q} * \mathrm{~N}_{(1 \times \mathrm{n})} * \mathrm{~T}_{(\mathrm{n} \times \mathrm{k}+1)} * \mathrm{~dB}_{(\mathrm{k}+1 \times 1)}
\end{aligned}
$$

To hedge the position's value risk against factor shifts, choose a hedge position such that 


$$
\mathrm{N}_{(1 \times \mathrm{n})} * \mathrm{~T}_{(\mathrm{nxk}+1)}=0
$$

Ignore the trivial solution and normalize the position by choosing $\mathrm{N}_{1}=1$. Then, solve this homogeneous equation system by the usual matrix methods. Under the hedge condition, the sum of the loadings on each of the $\mathrm{k}+1$ factors weighted by the chosen positions in each contract equals zero.

To implement the model for pricing and hedging, estimate the unobservable implicit factors and their corresponding loadings for each element of the interest rate vector from a sample of historical data. Garbade (1996) and Litterman and Scheinkman (1991) present such analyses for US Treasury market data. They find that three factors approximate the data well, though Garbade's evidence indicates the presence of a higher number of less important factors. Using the resulting factor loading estimates, the hedge positions follow from equation (4).

This "implicit factor" approach troubles some economists who believe that interest rate and securities price fluctuations should be tied to observable real and monetary variables. For practitioners, the main concern is whether the estimated empirical system remains stable over time. Current pricing and hedging decisions, even if the number of factors is known and constant, depend on the estimated factor loadings. These estimates - apparently unbiased and efficient in the historical sample period - may still be inappropriate for the future. Because the hedge positions are constructed based upon historical estimates, future hedge performance is subject to potentially ruinous coefficient shifts. Garbade's evidence suggests that significant instability may exist in estimated coefficients over different time periods. 
Estimation specifics aside, the hedge solution will correspond to well-known spanning conditions. To span the set of $\mathrm{k}+1$ risks in the forward interest rate curve, the hedge solution must invoke $\mathrm{k}+2$ different contracts. For example, the simplest risk model is a flat term structure $(\mathrm{k}=0)$. Only the common "level" of forward rates fluctuates. Just two contracts are needed to hedge this risk structure $(\mathrm{k}+2=2)$. In contrast, if a second factor (a "slope term") also enters, three contracts are needed. If a third factor (a "curvature term") enters, four contracts will be needed to span the portfolio's risk structure. For hedging to be complete, the number of available contracts in the deposit rate strip under consideration must exceed the $\mathrm{k}+1$ number of hypothesized factors $(n>k+1)$. If $n>k+2$, then more than one set of $k+2$ contract strips can be constructed as factor-risk hedge positions. The evidence cited above that three factors explain the bulk of fluctuations in the US Treasury yield curve implies that positions in at least four contracts are needed to control the main sources of interest rate risk.

\section{Polynomial Interpretations}

A polynomial function is one special representation for the yield curve in (1). Following Chambers, Carleton and Waldman, the vector of forward interest rates can be approximated by a suitably chosen high-order polynomial function of time to maturity. Denote the time to maturity of the $\mathrm{i}^{\text {th }}$ contract by $\mathrm{t}_{\mathrm{i}}$. For a $\mathrm{k}^{\text {th }}$-degree model, populating the $\mathrm{T}_{(\mathrm{n} \times \mathrm{k}+1)}$ matrix is straightforward: 


\begin{tabular}{|c|c|c|c|c|c|}
\hline \multirow{5}{*}{$\mathrm{T}_{(\mathrm{n} \times \mathrm{k}+1)}=$} & 1 & $\mathrm{t}_{1}$ & $\mathrm{t}_{1}^{2}$ & ... & $\mathrm{t}_{1}{ }^{\mathrm{k}}$ \\
\hline & 1 & $\mathrm{t}_{2}$ & $\mathrm{t}_{2}{ }^{2}$ & $\ldots$ & $\mathrm{t}_{2}{ }^{\mathrm{k}}$ \\
\hline & 1 & $\mathrm{t}_{3}$ & $\mathrm{t}_{3}{ }^{2}$ & $\cdots$ & $\mathrm{t}_{3}{ }^{\mathrm{k}}$ \\
\hline & • & • & • & $\cdots$ & • \\
\hline & 1 & $t_{n}$ & $\mathrm{t}_{\mathrm{n}}^{2}$ & $\ldots$ & $\mathrm{t}_{\mathrm{n}}{ }^{\mathrm{k}}$ \\
\hline
\end{tabular}

Immediately, a polynomial representation has two virtues. First, the T matrix is observable and predetermined. Second, the $\mathrm{B}_{(\mathrm{k}+1 \times 1)}$ vector now implies more concrete indexes of yield curve level, slope, curvature, etc.

One property of a polynomial yield curve representation is the precise form of the hedging solutions (4) for a strip with n equally spaced constant maturities. Substituting the maturities (here measured as periodic distances versus the maturity of the first contract), $\mathrm{T}_{(\mathrm{n} \times \mathrm{k}+1)}$ becomes

$\begin{array}{cccccc} & 1 & 0 & 0 & \cdots & 0 \\ \mathrm{~T}_{(\mathrm{n} \times \mathrm{k}+1)}= & 1 & 1 & 1 & \ldots & 1 \\ & 1 & 2 & 4 & \ldots & 2^{\mathrm{k}} \\ & & \cdot & \cdot & \cdots & \cdot \\ & 1 & (\mathrm{n}-1) & (\mathrm{n}-1)^{2} & \ldots & (\mathrm{n}-1)^{\mathrm{k}}\end{array}$


Given such a structure, the hedge solutions correspond to a progression of simple quantity differencings of adjacent contracts. First differences - the $\left(\mathrm{N}_{1}=1 ; \mathrm{N}_{2}=-1\right)$ spread - will hedge shifts in the level of rates $\left(\mathrm{dB}_{0}\right)$. Second differences - the $\left(\mathrm{N}_{1}=1 ; \mathrm{N}_{2}=-2 ; \mathrm{N}_{3}=1\right)$ butterfly will hedge both the level and slope shifts $\left(\mathrm{dB}_{0}\right.$ and $\left.\mathrm{dB}_{1}\right)$. Third differences - the $\left(\mathrm{N}_{1}=1 ; \mathrm{N}_{2}=-\right.$ $\left.3 ; \mathrm{N}_{3}=3 ; \mathrm{N}_{4}=-1\right)$ box - will hedge level, slope and curvature shifts $\left(\mathrm{dB}_{0}, \mathrm{~dB}_{1}\right.$ and $\left.\mathrm{dB}_{2}\right)$. Likewise, $(\mathrm{k}+1)$-order differences - i.e., $\mathrm{k}+1$ spreads involving $\mathrm{k}+2$ contracts - will hedge shifts in $\mathrm{k}+1$ pricing terms.

Table 1 summarizes the problem's hedge solutions for an increasingly higher-ordered $\mathrm{k}^{\text {th }}$-degree polynomial (given $\mathrm{N}_{1}=1$ ). The diagram neatly reveals that the absolute magnitudes of the hedge solutions correspond to Pascal's Triangle. Overlaying an additional unit structure of alternating long and short contract positions (+ and - signs) delivers "Pascal's Spreading Triangle."

< Insert Table 1 Here>

The polynomial curve representation of the deposit rate term structure implies that hedging and trading of short-term interest rate contracts reduces to analyzing sequences of adjacent spreads. Each degree of higher polynomial order corresponds to another level of spreading: the simple spread; the butterfly; the box; the spread of boxes; etc. Importantly, the hedge solution is constant over calendar time for a fixed value of $\mathrm{k}$. Thus, the initially 
appropriate hedged position (say, a 4-contract box spread for $\mathrm{k}=2$ ) remains the appropriate structure throughout the trading lives of the contracts involved.

Pascal spreads present an intuitive solution for controlling futures contract position risks for arbitrage trading. While serving intuition may be a goal itself, this approach's true advantage is its avoidance of estimation procedures. Pascal spreads are predetermined and do not rely on coefficients estimated from historical data. In contrast, factor models need not reduce to such simple trading rules. And if the $\mathrm{k}^{\text {th }}$-degree polynomial approximation is accurately determined, the Pascal hedging and pricing results should be equivalent to those from the alternative factor approach. Of course, an appropriately large number of adjacent contracts must be included in the strip. But since most major deposit futures markets list strips of eight, twelve, sixteen, or even forty contract maturities, the $\mathrm{n}>\mathrm{k}+1$ constraint should not be binding in practice.

Finally, equation (1) views the strip of forward interest rates as an exact function of a limited number of common factors. Relax this restriction by introducing a vector of individual contract transitory pricing disturbance terms, $\mathrm{e}_{(\mathrm{k}+2 \times 1)}$. Still, choose the polynomial order $\mathrm{k}$ correctly. Then, interpret the value for the properly differenced $k+2$ contract Pascal spread as a transitory pricing disturbance term equal to a weighted sum of individual disturbance terms of each included contract. The correctly differenced spread time series, $\mathrm{e}^{\mathrm{s}}$, is actually the weighted sum of the Pascal spread weights from Table $1, \mathrm{~N}_{(1 \times \mathrm{k}+2)}^{\mathrm{s}}$, multiplied by $\mathrm{e}_{(\mathrm{k}+2 \times 1)}$, the individual transitory pricing disturbance terms on each contract included in the $\mathrm{k}+2$ contract strip:

$$
\mathrm{e}^{\mathrm{s}}=\mathrm{N}_{(1 \times \mathrm{k}+2)}^{\mathrm{s}} * \mathrm{e}_{(\mathrm{k}+2 \times 1)} \text {. }
$$


For the correct choice of the polynomial order k, the appropriately differenced Pascal spread has a mean value of zero.

The correctly differenced spread's variance should equal that of the transitory pricing disturbance term, $\mathrm{e}^{\mathrm{s}}$. The separate time series dimension of the correctly differenced spread position invites analysis of potential arbitrage opportunities (around the appropriate zero mean). Analyzing arbitrage possibilities also entails delineating appropriate transactions costs for trading these structures.

\section{The Data}

This empirical investigation applies the Pascal spreading analysis to the United Kingdom's Short Sterling deposit rate futures market. Short Sterling futures are traded on the London International Financial Futures Exchange (LIFFE). Because the Bank of England tends to smooth out end-of-year shocks - at least prior to the Y2K event - December distortions have been nearly non-existent. Thus, interpreting December-inclusive strips involves no separate analysis of the average year-end price discount. ${ }^{5}$ The absence of year-end distortions in the UK makes the Short Sterling futures market extremely convenient for analyzing Pascal spreading. ${ }^{6}$

Contract values mark to the market daily against official daily settlement prices as determined by the exchange. An expiring contract's final settlement price is determined externally by the expiration day's official British Bankers Association Sterling LIBOR fixing. The data are daily settlement prices on the first eight contracts (the front four settlement months 
and the "red" or second four settlement months) from January 4, 1989 to September 15, 1998 excluding contract expiration days. ${ }^{7}$ The sample includes 2,374 days of data.

The analysis categorizes the Pascal spreads as constant strip position entities. Constant strip position entities organize the data solely by position in the strip. For example, on a specific sample date - say, February 15, 1994 - classify the March94-June94 spread as the "first spread"; the June94-September94 spread as the "second spread"; and so on. Likewise, classify the March94-June-94-September94 as the "first butterfly"; the June94-September94December94 butterfly as the "second butterfly"; and so on. The more highly differenced positions are tagged in a like manner. For each spread type, a given number of strip contract positions exist: seven two-contract spreads; six three-contract butterflies; five four-contract boxes; and so on. The time series for these constant maturity constructs span the entire length of the sample period.

Of course, proper interpretation of all spread trading data requires understanding transactions costs. Commission costs have fallen dramatically over the ten-year period under study. Early in this sample period, an off-the-floor high-volume spread trader's round-turn commission expenses for entry and exit of a Short Sterling contract would have been about 5 pounds sterling ( 3 pounds for execution and 2 pounds for clearing charges and fees). By the middle of the period, costs would have totaled nearer to 4 pounds per round turn. By the end of the sample period, costs would have been closer to 2.25 pounds per round turn. ${ }^{8}$

To gauge the trading impact of such transactions costs, express them in terms of contract price basis points. For the 3-month, 500,000 pounds sterling notional contract's 1- 
basis point price change value of 12.5 pounds sterling, direct commission costs of 5 pounds equal 0.4 basis points; costs of 4 pounds equal .32 basis points; and 2.25 pounds equal .18 basis points. The 1 by -4 by 6 by -4 by 1 fourth-differenced spread of boxes entails trading 16 $(=1+4+6+4+1)$ contracts. Thus, the properly scaled round-turn transactions cost of the fourth-order spread structure would be 6.7 basis points (=5/12.5 x 16) early on; 5.1 basis points $(=4 / 12.5 \times 16)$ in mid-sample; and 2.9 basis points $(=2.25 / 12.5 \times 16)$ more recently.

Finally, some sensitivity is needed to properly interpret spread constructs generated with settlement price data. An exchange official fixes official daily settlement prices shortly after the close of the regular trading session. For front month contracts, the settlement prices reflect the volume-weighted trading price in the last thirty seconds of trading. For less actively traded deferred contracts, the settlements respect the bids and offers in recognized spreads. Because of these procedures, settlement prices are more orderly than transactions prices. However, on average, successful value-oriented spread traders will tend to transact close to mid-market levels. ${ }^{9}$ Moreover, an apparently complex spread position can still be reasonably easy to transact. Consider the five-maturity sixteen-contract position required by a fourth-order Pascal spread. The position can be executed as a spread of two butterflies: long the first-third-fifth butterfly and short four times as many second-third-fourth contract butterflies. ${ }^{10}$

\section{Pascal Spread Results}

Table 2 reports summary statistics for seven types of Pascal spreads utilizing twothrough eight-contract packages. These seven types of spreads are derived from first- through seventh-differences along the contract strip. The contract weightings are those shown in the 
"Pascal Spreading Triangle" of Table 1. Here, the two-year contract strip availability delineates an eight-contract package as the limiting hedging order.

< Insert Table 2 Here>

For the time series of each of the seven Pascal spread structures, Table 2 presents the estimated sample means, standard deviations, standard deviation of the mean, the chi-square statistic testing the restriction that the sample mean equals zero, and sample autocorrelations. These results address two elemental questions. First, in the model's parlance, what is the appropriate k? Essentially, find the order of differencing where the Short Sterling data delivers Pascal spreads consistent with the zero mean spread value restriction. Second, does the polynomial term structure representation work equally well for all segments of the curve? Essentially, for a given $k$, examine whether biases emerge for Pascal spreads constructed over different ranges of included contracts.

Begin by analyzing the results for the first- and second-order differencings of the Short Sterling futures price data. For both simple two-contract spreads and three-contract butterflies, the chi-square statistics strongly reject the hypothesis that the mean spread value equals zero in almost every case. And even the exceptions - the third contract first-differenced spread and the fifth contract second-differenced spread - are suspect. Note that these case's close-tozero sample mean values can be viewed as axis intercept points in functions relating the mean spreads to time to maturity. The high absolute values (16 basis points on the lead contract 
simple spread; nearly 10 basis points in the second contract butterfly) of the estimated means indicate that the statistical rejections are economically significant.

Third-differenced spreads - four-contract boxes - fare somewhat better than the traditional simple two-contract spreads and three-contract butterfly spreads. While the data still soundly reject the zero mean restriction, the magnitudes of the estimated means (between one and five basis points) are generally lower than those for simple spread and butterflies.

Fourth-differences - spreads of boxes - begin to reasonably approximate the restrictions of the appropriately differenced Pascal spread. Except for the lead contract spread, the estimated mean spread values are within two basis points of zero. The test statistic for the third contract spread cannot reject the zero-mean restriction, while that for the fourth contract spread just barely rejects at the one-percent confidence level. Moreover, because the fourthdifferenced spread's autocorrelations dampen more quickly, this five-contract "spread of boxes" construct appears a better-specified structure for Short Sterling prices than the thirddifferenced box spread.

Fifth, sixth and seventh-order differencings produce similar results, though the estimated mean spreads involving the lead contract begin to become large again (about 10 basis points for fifth-differences; 12 basis points for sixth differences; and about 17 basis points for seventhdifferences).

One consistent finding is that - for this sample period - spreads involving the front contract perform poorly. For all orders of differencings, front contract spreads soundly reject 
the zero mean restriction. Furthermore, the estimated mean values for front contract spreads are large in absolute value.

Table 3 reports summary statistics for the fourth-order Pascal spread - the spread of boxes - structure for five sub-periods: 1989-90; 1991-92; 1993-94; 1995-96; and 1997-98. These sub-period results reveal substantial shifts in the distribution of fourth-differenced Short Sterling spreads. Compare the results for the initial 1989-90 period with those for the final 1997-98 period. For all four spreads, the estimated mean spreads are closer to zero in the latter sub-period. Also, the estimated standard deviations are dramatically lower in the latter sub-period.

\section{<Insert Table 3 Here>}

The shifts in the estimates for the front contract spread between the first and last subperiods are particularly interesting. The estimated mean front spread value falls from +32.3 basis points to -1.1 basis point. The chi-square statistic on the zero mean restriction still rejects the null hypothesis in each case, but the computed statistic's value falls from 682.4 in the early subperiod to 22.7 in the final sub-period. Thus, the more recent data are far more consistent with the zero mean value suggested by the fourth-order polynomial term structure specification. Moreover, the spread's estimated standard deviation falls from 24.4 basis points to just 5.7 basis points. 
In sum, over most of the ten-year sample period studied, Pascal spreads based upon third- and, especially, fourth-order differences of Short Sterling deposit rate futures data provide reasonable descriptions of stationary series with mean values near zero.

\section{Value-Oriented Trading of Fourth-Order Spreads ("Arbitrage")}

This section investigates the dynamics of fluctuations in fourth-order Short Sterling

Pascal spreads and interprets changes in the volatility of such a "spread of boxes" in light of the transactions cost compression that has characterized futures trading over the last decade.

A reliable risk-controlled spread package is a vehicle through which value-oriented spread traders may enforce pricing discipline. Suppose that hedging or speculative pressures build in one particular contract maturity point. The individual price point pressures may become large enough for the market value of a risk-immunized spread construct to violate transactions cost bounds. Such violations should induce value-oriented spread trading. In turn, such spread trading should smooth out the single price point disturbance by transmitting it to surrounding contracts. During the transmission process, the spread traders provide liquidity to offset the specific initial hedging or speculative pressure. These spread trades will be profitable if the initial pressure on the curve reverses sufficiently before the spread position is unwound. Thus, the focus of the study now shifts from restrictions on the mean to the spread's time series behavior.

Figures 1 and 2 plot the fourth-differenced values for the front and fourth contract series, respectively, over the ten-year sample period. These figures clearly illustrate two points. First, the front spread's volatility (see Figure 1) is much larger than that of the deferred spread (Figure 2). Second, the volatilities of both of these spreads have declined markedly over the 
ten-year sample period. Some interesting fluctuations occur at the tail end of the sample for the fourth contract spread. These shifts reflect the structural impact of Y2K problems on Millennium-end financing costs to be embedded in a discount to the otherwise fair December 1999 contract's price (see Section 7 below).

Tables 4 and 5 present additional disaggregated results on the dynamics of fourth-order Short Sterling Pascal spreads for the first (1989-1990) and fifth (1997-1998) two-year subperiods. Each sub-period's daily spread data are ordered from highest to lowest and partitioned into value-ranked quintiles. Thus, in each table, the first quintile contains the richest spreads and the fifth quintile contains the cheapest spreads. Assume an ex ante mean spread estimate equal to zero. Then, from a value-oriented spread trader's perspective, initial spread values greater than zero indicate a "rich" spread. Such rich spreads should be sold. The spreader will benefit if the spread falls over the period of time before the position is closed-out. Conversely, initial spread values less than zero indicate a "cheap" spread. Cheap spreads should be purchased. Here, the spreader will benefit if the spread rises during the period before the position is unwound.

For each sub-period, spread contract strip position, and quintile, the tables report the average initial spread; the average subsequent 1-day, 5-day, and 10-day value changes; and the percentage frequency that these subsequent 1-day, 5-day, and 10-day value changes moved in the direction predicted by the initial value criteria. Only one serious contradiction of the simple "positive spread: richness" and "negative value spread: cheapness" rule occurs. In the earliest 1989-90 sub-period, the middle quintile's average value equals +31.1 . The middle quintile 
average values for the 1997-98 sub-period, as well as those for the 1991-92, 1993-94, and 1995-96 sub-periods (not shown), never differ as much as five basis points from the presumed ex ante value rule's presumed zero mean value. Paralleling Table 3's evidence of declining spread volatility throughout the ten-year period, the distance between the average spread richness (quintile 1 entries) and cheapness (quintile 5 entries) shrinks over time.

The process by which initially mispriced spreads return to value takes time. But, with the exception of the front contract, 1989-90 results mentioned above, the return-to-value process exhibits easily interpretable dynamics. The tables report on two dimensions of this dynamic process: the percentage frequency of the correct direction of subsequent changes and the magnitudes of these changes. In general, mispriced spreads move in the correct arbitrageconsistent direction more than $50 \%$ of the time for 1-day-ahead changes; and the percentage of correct direction changes increases as the length of the period is increased from 1-day to study 5-day and 10-day changes. Moreover, the accuracy of the plus-spread/minus-spread value ranking in predicting the direction of subsequent changes is highest for the initially most mispriced spreads (quintiles 1 and 5).

The holding period return to this type of term structure spread trading is uncertain. Unlike true arbitrage, initially misaligned spreads need not return to fair value prior to an individual position's unwind date. While the position unwind date is a choice variable, the limiting date is the maturity of the lead contract in the spread structure. On that maturity date, the structure breaks apart by definition. The trader is forced to unwind or roll the remaining components into a new structure with an uncertain capital gain, but with known commissions 
cost losses. Thus, transactions costs are crucial in determining a spread trader's entry and exit strategies. Furthermore, forced unwinds and rollovers entail consuming liquidity - trading at spreads worse than those implied by the settlement price data set. From this perspective at least, front contract spreads are different.

Rescaling the measured standard deviation of fourth-order spreads reported in Table 3 into transactions cost units reveals how Short Sterling pricing efficiency has improved over the ten-year sample period. For example, given the 6.7 and 2.9 basis point transactions cost estimate, the second contract spread's estimated standard deviation fell over the period from about 3 times costs $(=20.4 / 6.7$ for $1989-90)$ to just 1.4 times costs $(=4 / 2.9$ for $1997-98)$.

\section{Y2K in the UK: Millennium Turn Distortions in the Short Sterling Term Structure}

Figure 2 reveals unusual volatility in the five-contract spread of boxes structure during the final segment of the sample. A closer examination of the dating scheme of the affected spreads relates this unusual volatility to positions involving the December 1999 contract. The observed volatility results from the impact of the market's perception of unusual financing pressures over the "Millennium Turn." Such pressures would require the final mid-December three-month cash deposit rate - against which the December 1999 would have final cash settlement - to be set unusually high. Of course, as a consequence of this unusually high deposit rate, the December 1999 futures price would end unusually low.

Consider three five-contract spreads of boxes constituted with positions in the crucial December 1999 contract: 


$$
\begin{aligned}
& \text { S1 = Dec98 - 4*Mar99 + 6*Jun99 - 4*Sep99 + Dec99 } \\
& \text { S2 = Mar99 - 4*Jun99 + 6*Sep99 - 4*Dec99 + Mar00 } \\
& \text { S3 = Jun99 - 4*Sep99 + 6*Dec99 - 4*Mar00 + Jun00. }
\end{aligned}
$$

\begin{tabular}{|c|c|}
\hline Implied Dec99 Effect $1=$ & $\mathrm{S} 1$ \\
\hline Implied Dec99 Effect $2=$ & $-(\mathrm{S} 2) / 4$ \\
\hline
\end{tabular}

Assuming that the Millennium Turn effect-adjusted Pascal spread has a zero mean, the implied December 1999 price effect from each spread can be estimated:

A clearer picture of the Millennium Turn impact emerges from grouping these spread positions and computing the average December 1999 contract price effect for the common June 18, 1999 to September 15, 1999 sample period. Figure 5 presents the average Millennium Turn effect implied by the variable $S^{*}$ defined as:

$$
\mathrm{S}^{*}=(\mathrm{S} 1) / 3-(\mathrm{S} 2) / 12+(\mathrm{S} 3) / 18 .
$$

\section{$<$ Insert Figure 5 Here>}

For the first half of the period, the Millennium Turn generated a December 1999 Short Sterling contract price discount between 0 and 2 basis points. However, beginning in late July, the 
discount grew until it peaked at 8 basis points in latter weeks of August (in the midst of the Russian GKO default crisis). This December discount then receded toward its original 0 to 2 basis point range by the end of the period.

\section{Summary and Conclusions}

This paper develops a pricing and spreading framework for short-term interest rate futures contracts within the context of the high-order polynomial approximation approach to the term structure. The analysis produces some new insights into the natures of both spread trading design and risk structure along the yield curve. First, hedge positions producing stationary spread series relevant for value-oriented spread trading do exist. Second, the precise form of hedged trading conforms to an analytical solution termed here as "Pascal's Spreading Triangle." The solution collapses neatly to spreading sequences of adjacent contracts. Importantly, no empirically estimated hedge ratios are required to implement this spread trading paradigm.

Thus, not only can the high-order polynomial approach price a deposit contract strip arbitrarily well, but the model also delivers intuitive trading forms that are easily applied to maintain pricing discipline.

The approach is applied in a study of arbitrage efficiency in the LIFFE's Short Sterling deposit futures market. Analysis of five two-year sub-periods of daily Short Sterling futures price data reveals that the value-oriented spread trading (“arbitrage") sector's efficiency has improved markedly over time. The improved pricing efficiency is coincident with dramatic declines in transactions costs. Continued pressures on trading costs, driven by the momentum 
toward screen-based trading, most likely will ensure that the Short Sterling market will maintain its spread pricing efficiency gains.

Uncertainty related to the December 31, 1999 Y2K effect on Millennium-Turn financing costs caused significant distortions in the valuation of spread positions involving the December 1999 contract. A measure of the importance of this effect and its evolution over time was presented. While the passing of the December 1999 contract removes this specific distortion, new more subtle December effects for Short Sterling contracts may arise as the market anticipates a future UK entry into European Monetary Union and the concomitant conversion of Sterling deposit contracts into Euro deposit contracts. ${ }^{11}$ Thus, Short Sterling spreaders must now assess both the future date and probability of EMU entry as well estimate the fair value of each future December Euro contract's year-end financing pressure price discount. Unfortunately, as with all trading paradigms, real world complications tend to intrude. 


\section{Endnotes}

1. Working (1962) emphasizes the interplay of carrying charge mispricings and hedging. See Merrick (1988) for an empirical study of returns on stock portfolio hedges using initially mispriced stock index futures contracts.

2. The familiar restriction is implied comparing the rate on an $m+91$-day term interbank deposit with the synthetic m+91-day rate achievable by rolling over an original m-day deposit for the 91-day tail period at a rate effectively locked-in on day 0 through the purchase of an m-day-ahead maturity 3-month deposit futures rate.

3. The underlying yield curve function must be continuously differentiable over the range.

4. Critiques of the fitted results may revolve around whether the estimates generate smooth forward rate curves and provide sensible extrapolations outside the fitted maturity range. Polynomial term structure approximations have certain drawbacks. Estimates of forward rate curves derived from high-order polynomial curves may produce cyclic forward rate term structures. Moreover, forward rates extrapolated for maturities beyond the originally fitted maturity range may head off quickly toward infinity or else even turn negative. Alternatively, a spline function - a knotted sequence of low-order polynomial functions can be usefully applied to term structure modeling. For example, see McCulloch (1971), McCulloch (1975), Vasicek and Fong (1982) and Shea (1984). Many Wall Street practitioners promote spline functions as the basic building block for bond valuation. 
5. On average, the year-end bias in, say, December Eurodollar futures prices, was typically as high as fifteen basis points in the early 1990s. To gain more balance sheet freedom, the major dealing firms have gradually there own reporting dates off of the December $31^{\text {st }}$ cycle. The typical year-end effect for December Eurodollar futures has shrunk closer to the five basis point level. The Y2K distortion for the December 1999 contract is a separate phenomenon.

6. Short Sterling contract pricing maturity is also muddled even for post-1999 Decembers by the UK's prospects for joining European Monetary Union. Looking ahead, market participants must assess the probability and timing of a UK entry into EMU, and weigh the Bank of England's traditional year-end rate smoothing practices against the level of yearend distortions traditionally tolerated by the constituent central banks of the EMU countries (assuming the European Central Bank will behave as the constituent banks once did).

7. An additional four contracts (the "green" months) began trading in 1995. A fourth quartet of contracts (the "blue" months) began trading in 1997.

8. Initial margin balances, which can be met with interest-earning government securities, typically are an unimportant part of the trading equation. For practical purposes, the most important problem would be an unanticipated sharp sudden increase in margins.

9. Transactions by value-oriented spread traders need to be categorized into liquidityproducing trades and liquidity-consuming trades. Liquidity-producing trades are limit orders left working on the floor at, by definition, better-than-market levels. From time to time, real hedging and/or speculative demand - "paper" - appears with a need to trade large 
quantities of particular contracts. Value-oriented spreaders might then be lifted out of their better-than-market order levels through such flows. In contrast, liquidity-consuming trades represent transactions where spreaders must "pay up" to get desired trades done. Here, the spreaders would incur market impact costs, transacting at the full bid or offered side of the particular spread.

10. Or combine three second-third-fourth contract butterflies with single first-second contract and fourth-fifth contract spreads. This latter formulation is transactions cost efficient.

11. See footnote 6 above. 


\section{References}

Campbell, John Y., Andrew W. Lo and A. Craig MacKinlay (1997): The Econometrics of Financial Markets. Princeton University Press, Princeton, NJ.

Chambers, D.R., W.T. Carleton, and D.W. Waldman (1984): “A New Approach to Estimation of the Term Structure of Interest Rates," Journal of Financial and Quantitative Analysis, 19, 233-252.

Garbade, Kenneth D. (1996): Fixed Income Analytics. The MIT Press, Cambridge, MA.

Litterman, Robert and Jose Scheinkman (1991): "Common Factors Affecting Bond Returns," The Journal of Fixed Income, 1, 54-61.

McCulloch, J. (1971): "Measuring the Term Structure of Interest Rates," Journal of Business, 44, 19-31.

McCulloch, J. (1975): “The Tax-Adjusted Yield Curve,” The Journal of Finance, 30, 811830.

Merrick, John J., Jr. (1988): “Hedging with Mispriced Futures,” Journal of Financial and Quantitative Analysis, 23, 451-464.

Shea, Gary S. (1984): "Pitfalls in Smoothing Interest Rate Term Structure Data: Equilibrium Models and Spline Approximations," Journal of Financial and Quantitative Analysis, 19, 253-269.

Vasicek, O.A. and H.G. Fong (1982): “Term Structure Modeling Using Exponential Splines," The Journal of Finance, 37, 339-356.

Working, H. (1962): "New Concepts Concerning Futures Markets and Prices," American Economic Review, 52, 431-459. 
Table 1

Pascal's Spreading Triangle

Strip Hedge Solutions for $\mathbf{k}^{\text {th }}$-degree Polynomial Term Structure Functions

$\mathrm{k}+\mathbf{1} \quad \mathrm{k}+\mathbf{2}$

Risks Strip

Weightings on each adjacent contract in strip

$\begin{array}{ll}1 & 2 \\ 2 & 3 \\ 3 & 4 \\ 4 & 5 \\ 5 & 6 \\ 6 & 7 \\ 7 & 8 \\ . & .\end{array}$

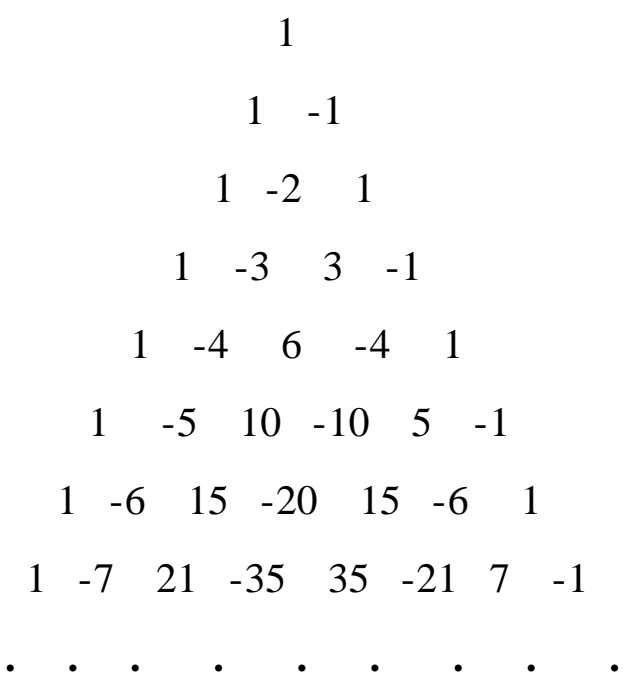


Table 2

Summary Statistics for Short Sterling Pascal Spread Structures

Sample Period: January 4, 1989 to September 15, 1998

\section{First Differences}

Mean

Std. Dev.

Std. Dev. of Mean

Chi-Square Statistic

Autocorrelations

$\begin{array}{rrrrrrrc} & \text { Front } & \text { Second } & \text { Third } & \text { Fourth } & \text { Fifth } & \text { Sixth } & \text { Seventh } \\ & -16.1 & -9.8 & -0.3 & 5.0 & 7.9 & 8.0 & 6.8 \\ & 46.4 & 39.3 & 31.4 & 26.5 & 21.8 & 17.9 & 14.5 \\ & 1.0 & 0.8 & 0.6 & 0.5 & 0.4 & 0.4 & 0.3 \\ & 270.9 & 144.2 & 0.2 & 82.0 & 294.7 & 435.5 & 472.5 \\ 1 & 0.997 & 0.998 & 0.998 & 0.997 & 0.996 & 0.993 & 0.997 \\ 5 & 0.987 & 0.987 & 0.987 & 0.986 & 0.983 & 0.973 & 0.986 \\ 10 & 0.976 & 0.978 & 0.975 & 0.974 & 0.968 & 0.952 & 0.974\end{array}$

\section{Second Differences}

Mean

Std. Dev.

Std. Dev. of Mean

Chi-Square Statistic Autocorrelations

\begin{tabular}{|c|c|c|c|c|c|c|}
\hline & Front & Second & Third & Fourth & Fifth & Sixth \\
\hline & -6.3 & -9.5 & -5.2 & -2.9 & -0.1 & 1.2 \\
\hline & 24.5 & 15.8 & 10.5 & 8.7 & 7.5 & 6.2 \\
\hline & 0.5 & 0.3 & 0.2 & 0.2 & 0.2 & 0.1 \\
\hline & 153.5 & 742.3 & 532.0 & 258.0 & 0.6 & 93.3 \\
\hline 1 & 0.988 & 0.986 & 0.974 & 0.964 & 0.947 & 0.916 \\
\hline 5 & 0.946 & 0.945 & 0.914 & 0.893 & 0.859 & 0.789 \\
\hline 10 & 0.900 & 0.909 & 0.844 & 0.827 & 0.784 & 0.727 \\
\hline
\end{tabular}

\section{Third Differences}

Mean

Std. Dev.

Std. Dev. Of Mean

Chi-Square Statistic

$\begin{array}{rrrrcc} & \text { Front } & \text { Second } & \text { Third } & \text { Fourth } & \text { Fifth } \\ & 3.2 & -4.3 & -2.3 & -2.8 & -1.4 \\ & 20.6 & 11.0 & 8.7 & 8.7 & 7.6 \\ & 0.4 & 0.2 & 0.2 & 0.2 & 0.2 \\ & 16.4 & 96.7 & 45.9 & 67.3 & 21.2 \\ 1 & 0.969 & 0.932 & 0.892 & 0.895 & 0.847 \\ 5 & 0.878 & 0.796 & 0.717 & 0.750 & 0.644 \\ 10 & 0.791 & 0.654 & 0.536 & 0.627 & 0.540\end{array}$


Table 2 (Continued)

Summary Statistics for Short Sterling Pascal Spread Structures

Sample Period: January 4, 1989 to September 15, 1998

\section{Fourth Differences}

Mean

Front Second Third Fourth

Std. Dev.

$$
7.5
$$

$-2.0$

$0.5 \quad-1.5$

Std. of Mean

22.6

$13.8 \quad 13.4 \quad 13.8$

Chi-Square Statistic

0.5

$\begin{array}{lll}0.3 & 0.3 & 0.3\end{array}$

Autocorrelations

70.9

14.0

$\begin{array}{ll}1.0 & 7.5\end{array}$

10.938

0.866

$0.852 \quad 0.855$

$\begin{array}{lllll}5 & 0.798 & 0.646 & 0.653 & 0.671\end{array}$

10

0.672

0.392

$0.465 \quad 0.547$

\section{Fifth Differences}

Mean

Front Second Third

Std. Dev.

$\begin{array}{lll}9.5 & -2.5 & 2.0\end{array}$

Std. of Mean

$30.8 \quad 24.1 \quad 24.9$

Chi-Square Statistic

$\begin{array}{lll}0.6 & 0.5 & 0.5\end{array}$

Autocorrelations

$\begin{array}{lll}61.9 & 7.3 & 4.2\end{array}$

$\begin{array}{llll}1 & 0.899 & 0.846 & 0.849\end{array}$

$\begin{array}{llll}5 & 0.717 & 0.628 & 0.661\end{array}$

$\begin{array}{llll}10 & 0.539 & 0.383 & 0.507\end{array}$

\section{Sixth Differences}

Mean

Front Second

Std. Dev.

12.0

$-4.5$

Std. Dev. of Mean

49.5

Chi-Square Statistic

$\begin{array}{ll}1.0 & 0.9\end{array}$

Autocorrelations

$38.9 \quad 6.5$

$1 \quad 0.868 \quad 0.844$

$\begin{array}{lll}5 & 0.663 & 0.641\end{array}$

$\begin{array}{lll}10 & 0.440 & 0.437\end{array}$

\section{Seventh Differences}

$\begin{array}{lrr} & & \text { Front } \\ \text { Mean } & & 16.6 \\ \text { Std. Dev. } & & 88.6 \\ \text { Std. Dev. of Mean } & & 1.8 \\ \text { Chi-Square Statistic } & & 23.2 \\ \text { Autocorrelations } & 1 & 0.850 \\ & 5 & 0.642 \\ & 10 & 0.412\end{array}$


Table 3

Summary Statistics for Short Sterling Fourth-Differences: "Spread of Boxes" Two-Year Sub-samples

Period: January 4, 1989 to December 31, 1990

Fourth Differences

\begin{tabular}{|c|c|c|c|c|c|}
\hline \multirow{2}{*}{ Mean } & & Front & Second & Third & Fourth \\
\hline & & 32.3 & -2.9 & 3.9 & -4.5 \\
\hline \multicolumn{2}{|l|}{ Std. Dev. } & 24.4 & 20.4 & 17.6 & 20.1 \\
\hline \multicolumn{2}{|c|}{ Std. Dev. of Mean } & 1.1 & 1.0 & 0.8 & 0.9 \\
\hline \multicolumn{2}{|c|}{ Chi-Square Statistic } & 682.4 & 13.2 & 32.3 & 32.4 \\
\hline \multirow[t]{3}{*}{ Autocorrelations } & 1 & 0.890 & 0.893 & 0.834 & 0.870 \\
\hline & 5 & 0.617 & 0.725 & 0.623 & 0.720 \\
\hline & 10 & 0.356 & 0.507 & 0.394 & 0.578 \\
\hline
\end{tabular}

Sample: January 2, 1991 to December 31, 1992

Fourth Differences

Mean

Std. Dev.

Std. Dev. of Mean

Chi-Square Statistic

Autocorrelations

\section{Front Second Third Fourth}

$\begin{array}{rrrr}4.3 & -4.1 & -0.3 & -0.9 \\ 28.6 & 18.1 & 19.6 & 17.9 \\ 1.3 & 0.8 & 0.9 & 0.8 \\ 15.0 & 34.0 & 0.2 & 1.8 \\ 0.947 & 0.888 & 0.904 & 0.872 \\ 0.800 & 0.616 & 0.701 & 0.645 \\ 0.704 & 0.321 & 0.557 & 0.511\end{array}$

Sample: January 4, 1993 to December 30, 1994

Fourth Differences

\begin{tabular}{|c|c|c|c|c|c|}
\hline \multirow{2}{*}{ Mean } & & Front & Second & \multirow{2}{*}{ Third } & \multirow{2}{*}{$\begin{array}{c}\text { Fourth } \\
-1.9\end{array}$} \\
\hline & & -0.9 & -0.5 & & \\
\hline Std. Dev. & & 15.7 & 11.4 & 8.9 & 7.9 \\
\hline Std. Dev. of Me & & 0.7 & 0.5 & 0.4 & 0.4 \\
\hline Chi-Square Stati & & 2.2 & 1.3 & 0.3 & 37.7 \\
\hline \multirow[t]{3}{*}{ Autocorrelations } & 1 & 0.870 & 0.786 & 0.652 & 0.550 \\
\hline & 5 & 0.652 & 0.556 & 0.378 & 0.146 \\
\hline & 10 & 0.408 & 0.221 & -0.038 & -0.051 \\
\hline
\end{tabular}


Table 3 (Continued)

Summary Statistics for Short Sterling Fourth-Differences: "Spread of Boxes" Two-Year Sub-samples

Sample: January 3, 1995 to December 31, 1996

Fourth Differences

\begin{tabular}{|c|c|c|c|c|c|}
\hline \multirow{2}{*}{ Mean } & & Front & Second & Third & Fourth \\
\hline & & 3.7 & -2.2 & -3.1 & 0.7 \\
\hline \multicolumn{2}{|l|}{ Std. Dev. } & 9.2 & 7.1 & 6.4 & 6.6 \\
\hline \multicolumn{2}{|c|}{ Std. Dev. of Mean } & 0.4 & 0.3 & 0.3 & 0.3 \\
\hline \multicolumn{2}{|c|}{ Chi-Square Statistic } & 103.4 & 63.8 & 144.5 & 7.0 \\
\hline \multirow[t]{3}{*}{ Autocorrelations } & 1 & 0.824 & 0.74 & 0.739 & 0.722 \\
\hline & 5 & 0.615 & 0.471 & 0.538 & 0.540 \\
\hline & 10 & 0.544 & 0.388 & 0.383 & 0.444 \\
\hline
\end{tabular}

Sample: January 2, 1997 to September 15, 1998

Fourth Differences

\begin{tabular}{|c|c|c|c|c|c|}
\hline \multirow{2}{*}{ Mean } & & Front & Second & Third & Fourth \\
\hline & & -1.1 & -0.1 & 2.5 & -0.9 \\
\hline Std. Dev. & & 5.7 & 4.0 & 7.1 & 10.8 \\
\hline \multicolumn{2}{|c|}{ Std. Dev. of Mean } & 0.3 & 0.2 & 0.3 & 0.5 \\
\hline \multicolumn{2}{|c|}{ Chi-Square Statistic } & 22.7 & 0.4 & 80.6 & 4.3 \\
\hline \multirow[t]{3}{*}{ Autocorrelations } & 1 & 0.747 & 0.578 & 0.892 & 0.947 \\
\hline & 5 & 0.352 & 0.234 & 0.800 & 0.884 \\
\hline & 10 & 0.025 & 0.148 & 0.775 & 0.890 \\
\hline
\end{tabular}


Table 4

Fourth-Differenced Short Sterling Spread Value Changes

Data Sorted into Value Ordered Quintiles

Sample Period: 1989-1990

Initial Avg. \% Times Correct

Quintile Spread Change Direction Avg. Change Avg. \% Change

1-day 5-day 10-day 1-day 5-day 10-day 1-day 5-day 10-day

Front Contract Spread

$\begin{array}{rrrrrrrrrrr}1 & 65.0 & 57 \% & 72 \% & 69 \% & -2.6 & -12.8 & -18.1 & -4 \% & -20 \% & -28 \% \\ 2 & 42.1 & 50 \% & 47 \% & 38 \% & -0.4 & 0.4 & 3.2 & -1 \% & 1 \% & 8 \% \\ 3 & 31.1 & 46 \% & 30 \% & 39 \% & -1.3 & 5.1 & 3.1 & -4 \% & 16 \% & 10 \% \\ 4 & 17.7 & 45 \% & 37 \% & 24 \% & 1.4 & 7.4 & 12.1 & 8 \% & 42 \% & 68 \% \\ 5 & -2.6 & 48 \% & 53 \% & 60 \% & 5.7 & 12.4 & 25.1 & -223 \% & -483 \% & -979 \%\end{array}$

\section{Second Contract Spread}

$\begin{array}{rrrrrrrrrrr}1 & 17.4 & 73 \% & 77 \% & 77 \% & -5.6 & -9.6 & -10.0 & -32 \% & -55 \% & -58 \% \\ 2 & 4.2 & 62 \% & 57 \% & 62 \% & -1.4 & -1.6 & 0.1 & -34 \% & -39 \% & 2 \% \\ 3 & -3.0 & 54 \% & 49 \% & 50 \% & 1.9 & 1.4 & 0.5 & -62 \% & -47 \% & -15 \% \\ 4 & -11.6 & 64 \% & 68 \% & 75 \% & 2.7 & 5.4 & 8.6 & -23 \% & -47 \% & -74 \% \\ 5 & -32.4 & 56 \% & 63 \% & 73 \% & 3.0 & 7.5 & 10.3 & -9 \% & -23 \% & -32 \%\end{array}$

\section{Third Contract Spread}

$\begin{array}{rrrrrrrrrrr}1 & 31.9 & 58 \% & 66 \% & 73 \% & -3.6 & -8.2 & -13.8 & -11 \% & -26 \% & -43 \% \\ 2 & 11.4 & 58 \% & 74 \% & 69 \% & -3.5 & -6.8 & -7.7 & -31 \% & -60 \% & -67 \% \\ 3 & 2.9 & 62 \% & 55 \% & 54 \% & -1.5 & -2.2 & -0.9 & -54 \% & -76 \% & -30 \% \\ 4 & -4.5 & 53 \% & 52 \% & 61 \% & 0.7 & 2.3 & 3.8 & -15 \% & -51 \% & -86 \% \\ 5 & -14.8 & 83 \% & 89 \% & 92 \% & 7.4 & 12.8 & 15.0 & -50 \% & -86 \% & -101 \%\end{array}$

\section{Fourth Contract Spread}

$\begin{array}{rrrrrrrrrrr}1 & 20.2 & 73 \% & 76 \% & 85 \% & -5.8 & -9.8 & -16.7 & -29 \% & -49 \% & -83 \% \\ 2 & 3.5 & 59 \% & 65 \% & 62 \% & 0.2 & -3.2 & -3.5 & 5 \% & -90 \% & -98 \% \\ 3 & -2.9 & 51 \% & 50 \% & 53 \% & -1.2 & 0.9 & 1.2 & 41 \% & -30 \% & -40 \% \\ 4 & -10.6 & 60 \% & 63 \% & 83 \% & 3.0 & 5.7 & 9.6 & -28 \% & -54 \% & -91 \% \\ 5 & -36.0 & 69 \% & 71 \% & 69 \% & 4.0 & 7.6 & 8.3 & -11 \% & -21 \% & -23 \%\end{array}$


Table 5

Fourth-Differenced Short Sterling Spread Value Changes

Data Sorted into Value Ordered Quintiles

Sample Period: 1997-1998

Initial Avg. \% Times Correct

Quintile Spread Change Direction Avg. Change Avg. \% Change

1-day 5-day 10-day 1-day 5-day 10-day 1-day 5-day 10-day

\section{Front Contract Spread}

$\begin{array}{rrrrrrrrrrr}1 & 6.5 & 69 \% & 72 \% & 90 \% & -1.7 & -3.8 & -6.8 & -26 \% & -59 \% & -105 \% \\ 2 & 1.8 & 68 \% & 75 \% & 72 \% & -1.4 & -2.4 & -3.2 & -80 \% & -136 \% & -178 \% \\ 3 & -0.7 & 47 \% & 51 \% & 55 \% & 0.4 & -0.7 & -0.3 & -48 \% & 92 \% & 41 \% \\ 4 & -3.5 & 62 \% & 71 \% & 73 \% & 0.9 & 2.2 & 2.7 & -25 \% & -64 \% & -79 \% \\ 5 & -8.7 & 74 \% & 79 \% & 88 \% & 2.0 & 5.1 & 7.5 & -22 \% & -59 \% & -86 \%\end{array}$

\section{Second Contract Spread}

$\begin{array}{rrrrrrrrrrr}1 & 5.2 & 79 \% & 85 \% & 88 \% & -2.4 & -3.9 & -4.6 & -46 \% & -74 \% & -88 \% \\ 2 & 2.0 & 61 \% & 69 \% & 65 \% & -0.8 & -1.1 & -1.4 & -40 \% & -54 \% & -69 \% \\ 3 & 0.2 & 49 \% & 42 \% & 55 \% & 0.3 & -0.4 & -0.6 & 141 \% & -219 \% & -330 \% \\ 4 & -2.0 & 63 \% & 64 \% & 71 \% & 1.2 & 1.6 & 2.0 & -61 \% & -80 \% & -102 \% \\ 5 & -6.5 & 71 \% & 79 \% & 88 \% & 1.8 & 4.0 & 5.3 & -28 \% & -62 \% & -81 \%\end{array}$

\section{Third Contract Spread}

$\begin{array}{rrrrrrrrrrr}1 & 14.3 & 57 \% & 51 \% & 57 \% & -0.8 & -1.2 & -1.2 & -6 \% & -9 \% & -9 \% \\ 2 & 3.3 & 74 \% & 71 \% & 68 \% & -1.8 & -2.0 & -1.7 & -54 \% & -61 \% & -52 \% \\ 3 & 0.5 & 51 \% & 53 \% & 48 \% & -0.5 & -0.9 & -0.4 & -83 \% & -158 \% & -78 \% \\ 4 & -1.4 & 60 \% & 55 \% & 63 \% & 0.9 & 0.9 & 1.0 & -67 \% & -67 \% & -74 \% \\ 5 & -4.1 & 71 \% & 75 \% & 81 \% & 2.0 & 3.4 & 3.1 & -48 \% & -81 \% & -75 \%\end{array}$

\section{Fourth Contract Spread}

$\begin{array}{rrrrrrrrrrr}1 & 11.4 & 63 \% & 67 \% & 63 \% & -1.1 & -2.0 & -2.0 & -9 \% & -17 \% & -17 \% \\ 2 & 4.2 & 67 \% & 76 \% & 81 \% & -1.7 & -2.3 & -2.6 & -40 \% & -55 \% & -64 \% \\ 3 & 1.2 & 45 \% & 44 \% & 53 \% & 0.1 & 0.4 & -0.3 & 9 \% & 30 \% & -22 \% \\ 4 & -1.6 & 71 \% & 70 \% & 67 \% & 1.6 & 1.9 & 1.6 & -98 \% & -118 \% & -102 \% \\ 5 & -17.4 & 52 \% & 48 \% & 45 \% & 1.0 & 0.7 & -0.5 & -6 \% & -4 \% & 3 \%\end{array}$




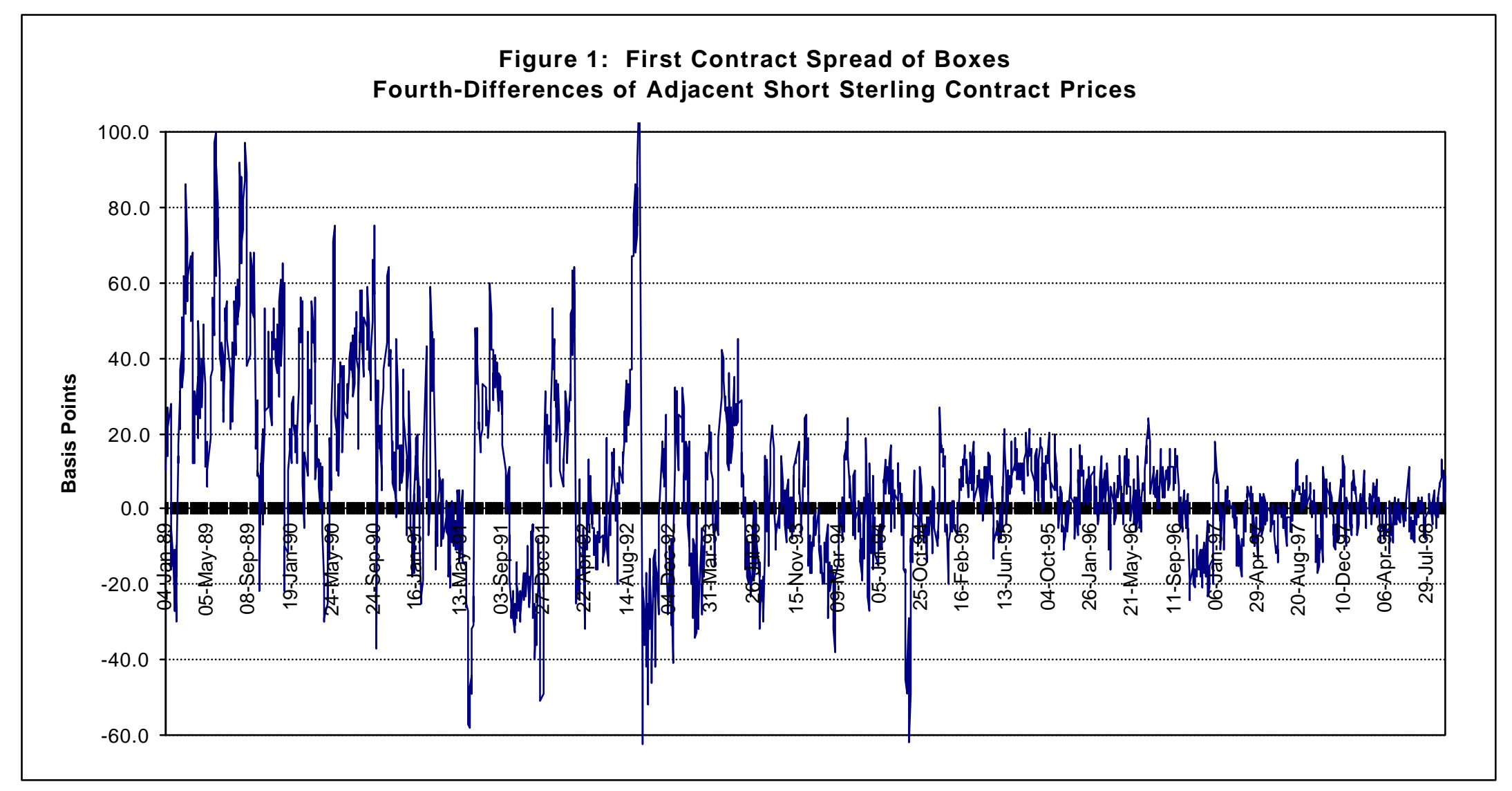




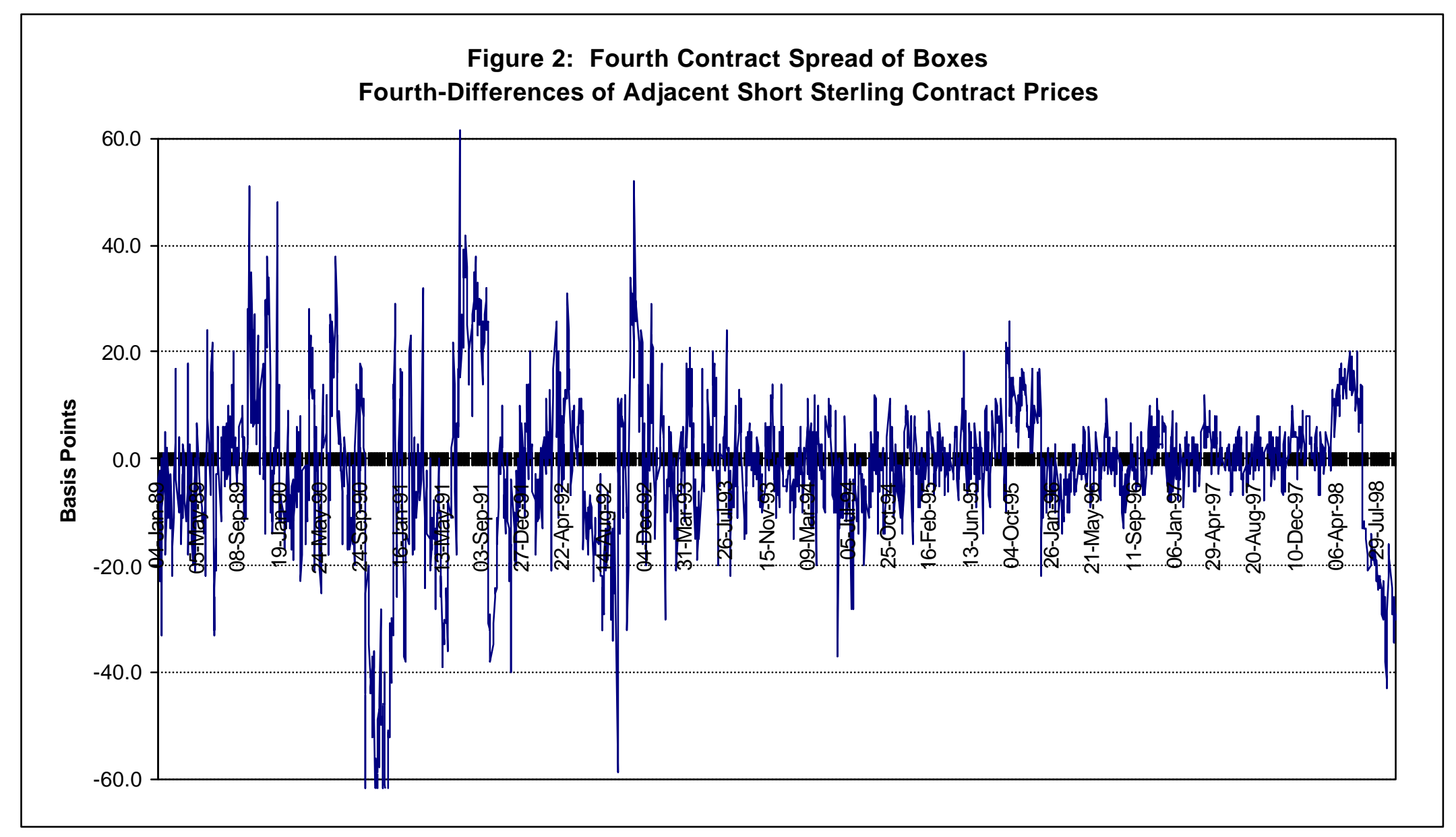




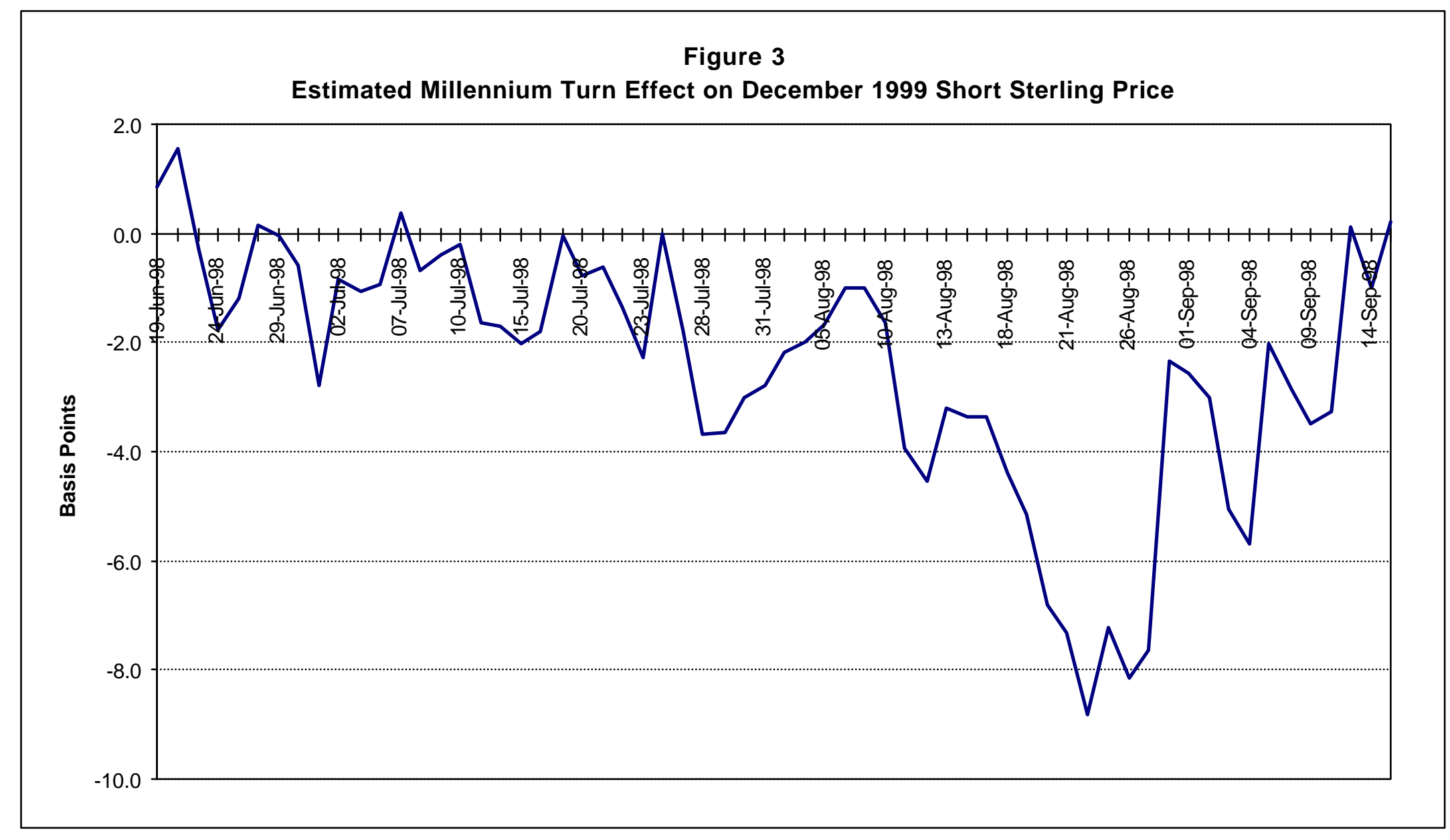

